Article

\title{
Improving Blowout Performance of the Conical Swirler Combustor by Employing Two Parts of Fuel at Low Operating Condition
}

\author{
Yixiang Yuan ${ }^{1,2}$, Qinghua Zeng ${ }^{3, *}$, Jun Yao ${ }^{1}$, Yongjun Zhang ${ }^{3}$, Mengmeng Zhao ${ }^{4, *}$ (i) and Lu Zhao ${ }^{1,2}$ \\ 1 Institute of Engineering Thermophysics, Chinese Academy of Sciences, Beijing 100190, China; \\ yuanyx@iet.cn (Y.Y.); yaojun@iet.cn (J.Y.); saczll@163.com (L.Z.) \\ 2 University of the Chinese Academy of Sciences, Beijing 100049, China \\ 3 Institute for Aero Engine, Tsinghua University, Beijing 100084, China; zhangyongjun@tsinghua.edu.cn \\ 4 North China Institute of Aerospace Engineering, Langfang 065000, China \\ * Correspondence: zengqh@tsinghua.edu.cn (Q.Z.); mengezhao@gmail.com (M.Z.)
}

Citation: Yuan, Y.; Zeng, Q.; Yao, J.; Zhang, Y.; Zhao, M.; Zhao, L.

Improving Blowout Performance of the Conical Swirler Combustor by Employing Two Parts of Fuel at Low Operating Condition. Energies 2021, 14, 1681. https://doi.org/10.3390/ en14061681

Academic Editor: Phillip Ligrani

Received: 17 January 2021

Accepted: 9 March 2021

Published: 18 March 2021

Publisher's Note: MDPI stays neutral with regard to jurisdictional claims in published maps and institutional affiliations.

Copyright: (C) 2021 by the authors. Licensee MDPI, Basel, Switzerland. This article is an open access article distributed under the terms and conditions of the Creative Commons Attribution (CC BY) license (https:/ / creativecommons.org/licenses/by/ $4.0 /)$.

\begin{abstract}
Aiming at the problem of the narrow combustion stability boundary, a conical swirler was designed and constructed based on the concept of fuel distribution. The blowout performance was studied at specified low operating conditions by a combination of experimental testing and numerical simulations. Research results indicate that the technique of the fuel distribution can enhance the combustion stability and widen the boundary of flameout within the range of testing conditions. The increase of the fuel distribution ratio improves the combustion stability but leads to an increase in NOx emission simultaneously. The simulation results show the increase of the fuel distribution ratio causes contact ratio increase in the area of lower reference velocity and gas temperature increase. The increased contact ratio and temperature contribute to the blowout performance enhancement, which is identical to the analysis result of the Damkohler number. The reported work in this paper has potential application value for the development of an industrial burner and combustor with high stability and low NOx emission, especially when the combustion system is required to be stable and efficient at low working conditions.
\end{abstract}

Keywords: fuel distribution ratio; combustor; damkohler number; blowout; operating condition

\section{Introduction}

In recent years, with the continual improvement of environmental requirements, the discharge standard of pollutants has become increasingly strict. Premixed or partly premixed combustion as one of the low NOx emission technologies has the best prospect for both civil and industrial applications. Among three formation paths of NOx [1,2], thermal NOx is generated by the chemical reaction of $\mathrm{N}_{2}$ and $\mathrm{O}_{2}$ in the combustion air at high-temperature combusting conditions. The formation of thermal NOx needs to be considered for hydrocarbon fuel because the higher the combustion temperature is, the more thermal NOx produced. Thus, if the combustion temperature is controlled at a relatively low level, the NOx emission will be reduced dramatically. Currently, various efforts have been made to keep the temperature of the combustion zone as low as possible. One of these methods is to use the lean premixed combustion system in the manner of mixing the fuel and air uniformly with a lean equivalence ratio before the combustion reaction happens. The lean premixed combustion can generate a relatively low average temperature and avoid the occurrence of high temperature hotspot so that the formation of thermal NOx in the reaction flow is inhibited effectively [3]. Nowadays the lean premixed combustion system has been used broadly in the restoration of oxynitride in the combustion apparatus [4,5].

However, the improvement of the premixed level will bring the stability problem in the lean premixed combustion system, [6-9], especially under low operating condition or 
when the fuel is of medium/low calorific value. It is difficult to improve the premixed level while to maintain the combustion with the same stability boundary. In order to solve this problem, some typical dome structures, such as multi-swirler or long conical swirler were studied, as shown in Figure 1. The multi-swirler structure, consisting of a two-stage or three-stage swirler as shown in Figure 1a, is the most common used in a combustor [10,11]. The modes of the swirler includes the axial type, radial type and tangential type [12,13]. The deflection component is used in the multi-swirler structure to produce rotating air that can accelerate the mixing process of air and fuel. In past studies, the counter-rotating dual-stage swirler has been investigated intensively and some regularity recognitions have been concluded $[14,15]$. In this kind of multi-swirler structure, the incoming air flow in each stage of the swirl structure is mainly distributed due to the resistance characteristics. However, it is difficult to control each stage of swirl flow actively and accurately. Based on the philosophy of premixed or semi-premixed pattern of the eddy mechanism, the long conical swirler was proposed for lean premixed combustion system by supplying gas fuel on the opposite sides of the cone combustor, as shown in Figure 1b. In this type of swirler, the air enters the cone chamber tangentially while the fuel penetrates the air flow through the injection hole located at the air entrance nearby and mixes with the air further within swirling flow downstream. Fernando et al. [16] studied the relationship between the flame stable position and the dynamic pressure change in the long conical swirler dome combustor. Sohn et al. [17] analyzed the suppression mechanism of a conical swirler dome combustor and concluded that the combustion instability was restrained by increasing the inlet temperature. Zajadatz et al. [5] and Xiaoming et al. [18] injected part of the fuel from the top of the conical swirler and found that the pressure fluctuation in the combustion chamber was reduced significantly. Guyot et al. [19] applied the multi-swirler scheme by injecting part of the fuel through upper side conical swirler to the gas turbine annular combustion chamber on the basis of report [5] and found that combustion stability was improved significantly. Although the long cone-shaped swirler has been developed and applied in the gas turbine combustor by the power companies [20,21], it has the specific instability problem about lean premixed combustion under low operating conditions.

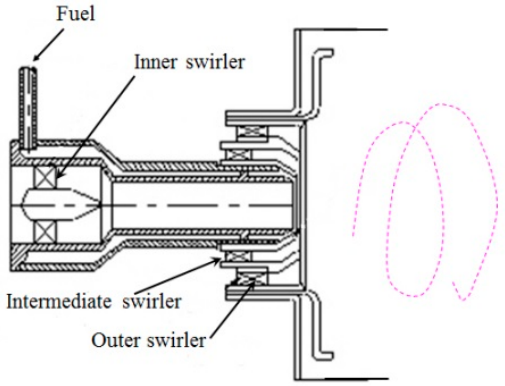

(a)

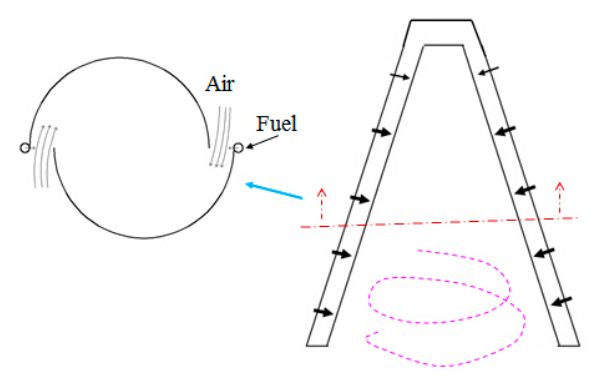

(b)

Figure 1. Different structure of combustor swirler: (a) multi-swirler (b) long conical swirler.

To solve the issue of combustion instability at low operating condition, a conical swirler is introduced in this paper, as shown in Figures 2 and 3. The fuel delivery is divided into two streams at low operating conditions-Part A fuel is injected into the combustor chamber from the top of the combustor, while Part B fuel, similar to the design of A. H. Lefebvre [4], is injected at the air entrance flowing with incoming air into the cone combustor. Compared to the previous design of a conical swirler utilizing only Part A fuel or Part B fuel at low operating condition, the present technique using two streams of fuel injection can enhance the combustion performance and broaden the stable boundary of the combustor or burner. 

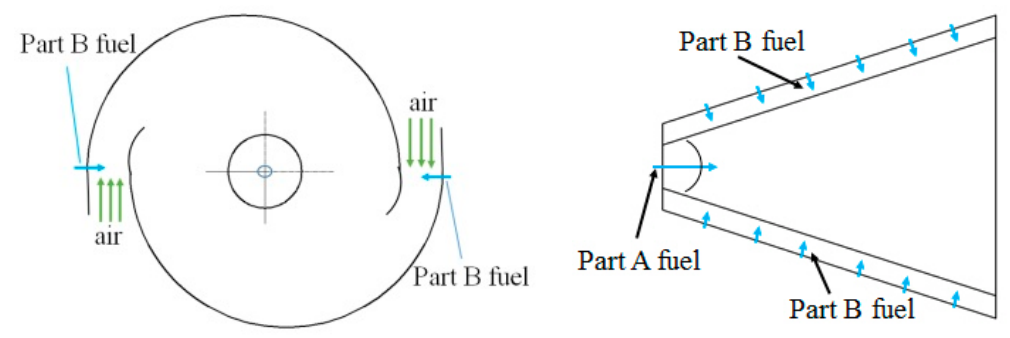

Figure 2. Schematic diagram of conical swirler at low operating condition.

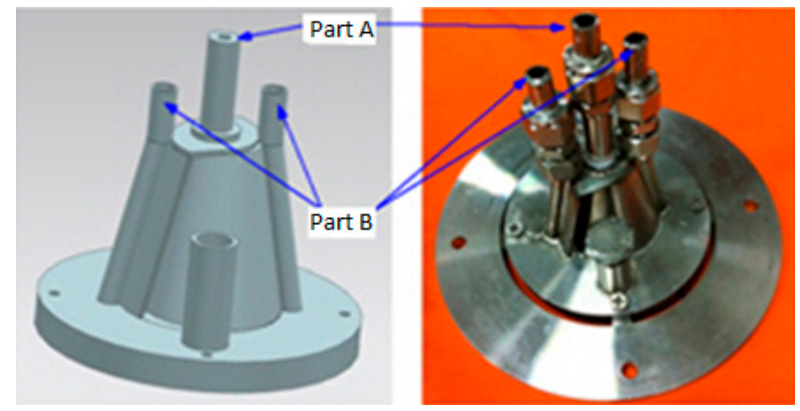

Figure 3. Model (left) and the physical object (right) of the conical swirler with two parts of fuel.

Research about the fuel distribution between Part A and Part B illustrated that it could influence significantly on the combustor's performance [18,22-26]. Lin et al. [27] studied the influence of fuel distribution on the ignition of an internal combustion engine. Zeng et al. [28] studied the influence of fuel distribution on NOx emission in dual-swirling combustor. As we proposed a conical swirler with a different fuel supply scheme at low operating condition, knowledge from previous studies is not valid for the present conical swirler in this paper. In order to improve the performance of conical swirler for potential applications in future, the investigation of the influence of fuel distribution on the blowout performance and boundary of combustion stability at the low condition were performed by a combination of experimental testing and numerical simulation.

\section{Fuel Distribution Ratio at Low Operating Condition}

To reduce the NOx emission and improve the combustion stability of the combustor, researchers have introduced some measures, of which the key technic is about the improvement of fuel/air mixing quality by optimizing the cone combustor structure and the fuel supply scheme $[1,23,24]$. The conical swirler with improved fuel/air mixing technic in this paper is shown in Figure 3. Two separate pipes with injector holes comprising the fuel delivery system of Part B are installed on the side surface of the cone. The transverse fuel jet produced by Part B mixing with incoming air forms a swirling flow in the cone chamber. Part A fuel is injected into the cone chamber penetrating into and mixing with swirling fuel/air mixture.

When the fuels in Part A and in Part B work together at low operating conditions, the fuel distribution between Part A and Part B needs to be tuned to optimize the blowout performance and to achieve a stabilized combustion flame. Regarding the high load working conditions, the continued increase of the gas content of Part B will lead to a more uniform mixture of fuel and air and result in the reduction of NOx emission.

For the low operating conditions, the fuel distribution ratio also plays an important role in the combustion stability and NOx emission. The distribution ratio is defined as:

$$
R_{a, l o w}=\dot{m}_{P a r t, A} /\left(\dot{m}_{P a r t, A}+\dot{m}_{P a r t, B}\right)
$$

where $\dot{m}_{P a r t, A}$ and $\dot{m}_{P a r t, B}$ are the fuel mass flow rate in Part A and Part B, respectively. 


\section{Testing System}

\subsection{Model Combustor and Experiment Rig}

The conical swirler is mounted onto the upstream side of model combustor, as shown in Figure 4. The fuel for Part A and Part B are fed by two sets of the independent fuel supply system. The flame tube with the length of $560 \mathrm{~mm}$ is installed downstream of the conical swirler. The material of flame tube is silica glass with the ability to tolerate the harsh thermal stress and a transmittance as high as $90 \%$ for the requirement of optical measurement.

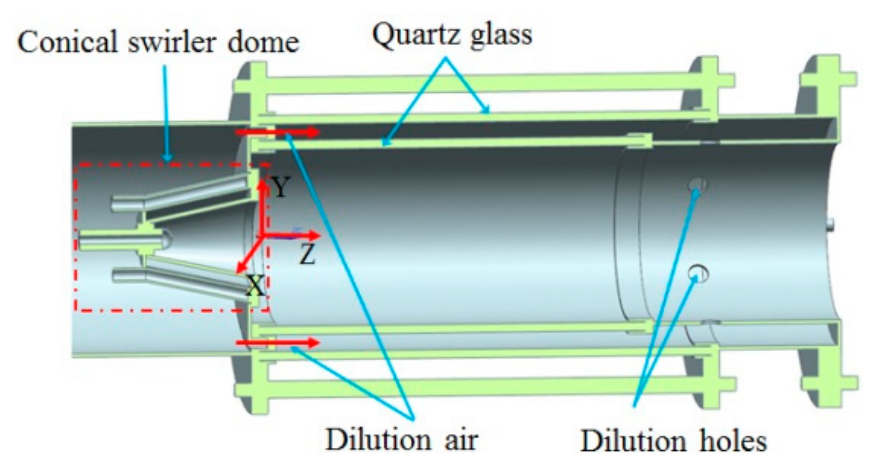

Figure 4. CAD view of the assembly of the conical swirler and model combustor.

The layout of the experimental facility, as shown in Figure 5, includes the air supply system, fuel supply system, combustion testing rig, data acquisition system, cooling system, flue gas analyzer, etc. The pressurized air is driven by a draught fan with a frequency converter and the flow rate is measured by a vortex shedding flowmeter with the accuracy of $1 \%$. The bottle fuel is divided into two streams entering the model combustor through Part A and Part B, separately. Two fuel flows are controlled by two sets of independent mass flow controller (brand name SEVENSTAR, type CS200, made in Beijing, China. The exhaust flue gas of the combustion product is cooled by the water jacket before the conduction of NOx testing. The NOx is measured by a flue gas analyzer (Testo-350) with the measuring range of $0-500 \mathrm{ppm}$, the resolution of $0.1 \mathrm{ppm}$, and measurement accuracy of $\pm 1 \mathrm{ppm}$ in the range of 0-99.9 ppm. The experimental data are acquired and analyzed by the software of LabVIEW [13].

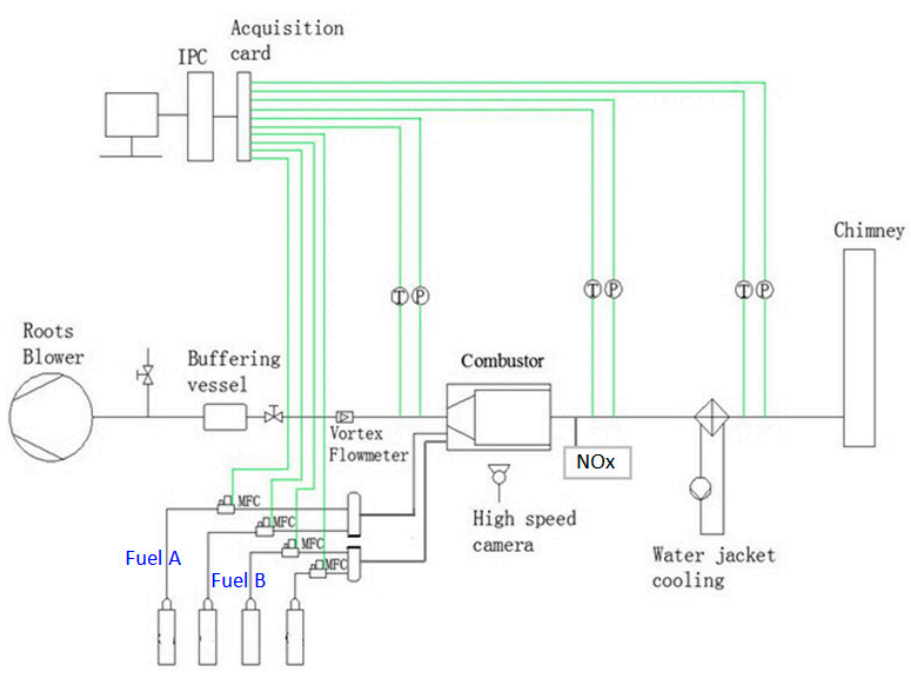

Figure 5. Layout of experimental setup.

\subsection{Experimental Process}

The experiment campaign was carried out at atmospheric pressure and ambient temperature of $25 \sim 26^{\circ} \mathrm{C}$. Gaseous methane is chosen as the fuel due to its convenience in 
purchase and good combustion performance. The experimental processes are as follows: (1) maintaining the air flow rate at a specified value; (2) fixing different constant values for Part A fuel flow rate; (3) regulating the flow rate of Part B fuel until the occurrence of flameout; and (4) repeating previous steps with the air flow rate at different values. A set of excess air coefficients corresponding to different working conditions can be calculated based on the recorded flow rates of air, Part A fuel and Part B fuel when flameout occurs.

\section{Experimental Results and Analysis}

Figure 6 shows the excess air coefficients of blowout and the reference velocity as a function of the air flow rate. Note that the profile marked " $\checkmark$ " represents the test with fuel supply for Part A and Part B simultaneously, and the profile marked " $\mathbf{\Lambda}$ " represents the test without Part A fuel. For cases of Part A and Part B working together, it can be seen that reference velocity increases linearly with air flow rate increasing, while the excess air coefficient decreases with air flow rate increasing. The reduction of excess coefficients indicates a gradual weakening combustion stability. To examine the effect of the Part A fuel on the overall performance of the improved conical swirler, fuel supply for Part A is shut down $\left(R_{a, \text { low }}=0\right)$ so it functions as the original long conical swirler as shown in Figure $1 \mathrm{~b}$.

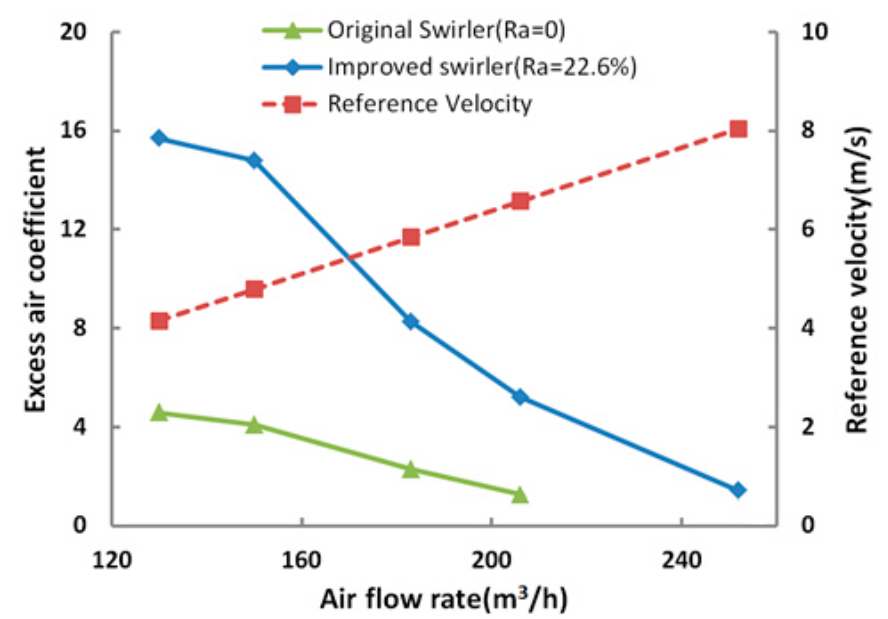

Figure 6. Excess air coefficient of blowout and reference velocity as function of air flow rate.

It is obvious that under the same air flow rate, the blowout excess air coefficient of the combustor with fuel fed by part A and part B is larger than that with Part B fuel only. The results demonstrate that compared to the traditional long cone swirler, the addition of part A fuel can improve the combustion stability and widen the blowout boundary for the modified cone swirler combustor.

In order to evaluate the effect of fuel distribution ratio on blowout performance, a fixed air flow rate is the necessary premise for the variation of the fuel distribution ratio. When the air flow rate is set to be $150 \mathrm{~m}^{3} / \mathrm{h}$, the experimental results of blowout excess air coefficients at different fuel distributions are listed in Table 1. For case 1 without fuel supply for Part A, the blowout excess air coefficient of the combustor is 3.9 with Part B fuel flow rate at $59.6 \mathrm{~L} / \mathrm{min}$. In case 2 , Part A is fueled at a constant flow rate of $1 \mathrm{~L} / \mathrm{min}$ and a stable flame remains in the combustor until the flameout occurs when the Part B fuel flow reduces gradually to $38 \mathrm{~L} / \mathrm{min}$. Compared to case 1 , the blowout excess air coefficient of combustor increases from 3.9 to 5.9 with addition of Part A fuel flow at the fuel distribution ratio $R_{a, \text { low }}$ of $2.6 \%$. For case 6 , the Part A fuel distribution ratio $R_{a, \text { low }}$ reaches to $40 \%$ while the blowout excess air coefficient of combustor increases to 22.9. By examining the experimental results from case 1 to case 6 , the similar trend can be found-That is, with the increase of Part A fuel flow rate and the reduced flow rate of Part B fuel at the flameout point, the increased blowout excess air coefficient is achieved. Thus, we can conclude that 
the conical swirler has an improved performance with a more stable combustion flame and a wider blowout boundary.

Table 1. Blowout excess air coefficient at different fuel distribution ratios.

\begin{tabular}{|c|c|c|c|c|c|}
\hline \multirow{2}{*}{ Case No. } & \multicolumn{3}{|c|}{ Fuel Flow Rate at Blowout (L/min) } & \multirow{2}{*}{$\begin{array}{l}R_{a, l o w} \\
\quad(\%)\end{array}$} & \multirow{2}{*}{$\begin{array}{c}\text { Excess Air Coefficient } \\
\text { at Blowout }\end{array}$} \\
\hline & $\dot{m}_{\text {Part }, A}$ & $\dot{m}_{P a r t, B}$ & $\dot{m}_{P a r t, A}+\dot{m}_{P a r t, B}$ & & \\
\hline case 1 & 0 & 59.6 & 59.6 & 0 & 3.9 \\
\hline case 2 & 1 & 38 & 39 & 2.6 & 5.9 \\
\hline case 3 & 2 & 23 & 25 & 8 & 9.2 \\
\hline case 4 & 3 & 17 & 20 & 15 & 11.5 \\
\hline case 5 & 3.5 & 12 & 15.5 & 22.6 & 14.8 \\
\hline case 6 & 4 & 6 & 10 & 40 & 22.9 \\
\hline
\end{tabular}

Table 2 shows the experimental results of cases from 7 to 11 regarding to the influence of fuel distribution ratio on the formation of combustion pollutant NOx at low operating condition and off blowout state. The excess air coefficient is calculated to be 4.8 and 5.18 for air flow rate at 70 and $120 \mathrm{~m}^{3} / \mathrm{h}$, respectively. The combustion flame in the combustor becomes stable until the $R_{a, \text { low }}$ reaches $5 \%$. Sustaining constant values of 4.8 or 5.18 for the total excess air coefficient, increasing the fuel distribution ratio results in a continuous increase of the NOx emission, as shown in Table 2.

Table 2. NOx formation off blowout state under different fuel distribution ratios.

\begin{tabular}{|c|c|c|c|c|c|c|c|}
\hline \multirow{2}{*}{ Case No. } & \multirow{2}{*}{$\begin{array}{l}\text { Air Flow Rate } \\
\qquad\left(\mathrm{m}^{3} / \mathrm{h}\right)\end{array}$} & \multicolumn{3}{|c|}{ Fuel Flow Rate (L/min) } & \multirow{2}{*}{$\begin{array}{c}R_{a, l o w} \\
(\%)\end{array}$} & \multirow{2}{*}{$\begin{array}{l}\text { Excess Air } \\
\text { Coefficient }\end{array}$} & \multirow{2}{*}{$\begin{array}{l}\text { NOx } \\
(p p m)\end{array}$} \\
\hline & & $\dot{m}_{\text {Part }, A}$ & $\dot{m}_{\text {Part }, B}$ & $\dot{m}_{\text {Part }, A}+\dot{m}_{\text {Part }, B}$ & & & \\
\hline case 7 & 70 & 5 & 18 & 23 & 21.7 & 4.8 & 4.1 \\
\hline case 8 & 70 & 4 & 19 & 23 & 17.4 & 4.8 & 3.9 \\
\hline case 9 & 70 & 3 & 20 & 23 & 13.0 & 4.8 & 3.2 \\
\hline case 10 & 120 & 8 & 29 & 37 & 21.6 & 5.18 & 5.5 \\
\hline case 11 & 120 & 5 & 32 & 37 & 13.5 & 5.18 & 3.5 \\
\hline
\end{tabular}

The analysis of the experimental data listed in Tables 1 and 2 shows the combustion stability of the combustor is improved but the NOx emission is worse with the increase of the fuel distribution ratio under a stable working condition.

\section{Numerical Computation and Analysis}

The discussion about experimental results indicates that the fuel distribution ratio has a significant influence on the swirler's performance, such as the flame stability and the blowout limit. Numerical simulations were performed for selected test cases in order to provide substantial insight into the flow structures and combustion phenomena of the conical swirler combustor.

The CFD code, FLUENT, was used for the modelling of the conical swirler combustor. The flamelet model coupled with a reduced methane chemistry mechanism was adopted for the turbulent combustion simulations $[29,30]$. Based on the concept of flame sheet, the flamelet approach assumes the chemical reaction is infinitely fast, and the reaction zone is infinitely thin. With the equal diffusivity assumption under constant pressure combustion without heat loss, the thermo-chemical properties are determined completely by the mixture fraction which describes the local mixing state. The flamelet model relaxes the infinitely fast chemistry assumption by introducing the scalar dissipation rate as a parameter to describe the degree of departure from the equilibrium state. The methane oxidation kinetics consists of 14 species and 26-step elementary reactions. The realizable $\mathrm{k}-\varepsilon$ model was used for the turbulence flow simulations. The unstructured meshes with 
4.2 million elements were used for the computational domain after the assessment of the grid-dependence study, as shown in Figure 7. The boundary conditions defined from the physical measurements were specified for numerical simulations. To explore the influence of the fuel distribution ratio on the combustion stability, the representative cases of 2 and 6 were chosen for numerical reconstruction because of the distinct difference of the blowout excess air coefficient caused by the fuel distribution ratio between these two cases.

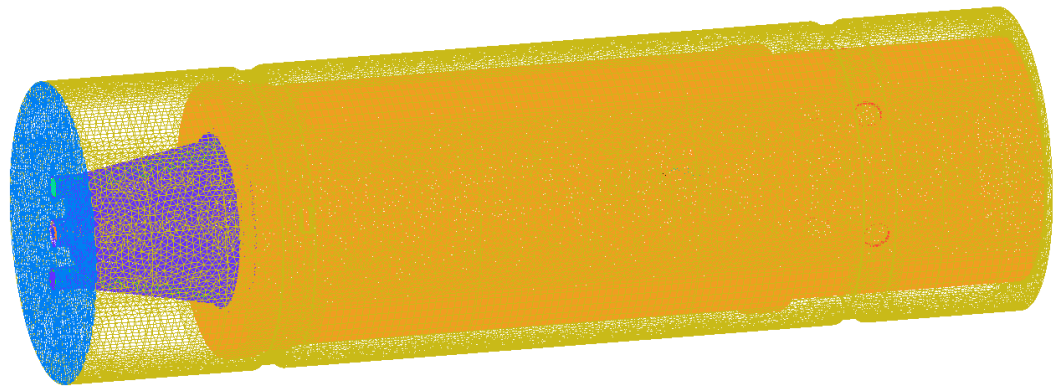

Figure 7. The computational meshes composed of the model combustor.

In general, a stable ignition zone with a lower reference velocity and higher temperature is necessary for the flame to exist and to keep stable in the combustor. Figure 8 shows the sectional distribution map of axial velocity at $Z=-50 \mathrm{~mm}$. The low velocity zones exist in the center of the cross section for both cases of 2 and 6 , but the high-speed rotating zones only appear in case 2 near the two half cones. Similar phenomena for sectional temperature distribution with high-temperature zones at the center of the $Z=-50 \mathrm{~mm}$ cross section can be observed, see Figure 9. Note that only case 2 has an annular high-temperature zone near the two semi cones.

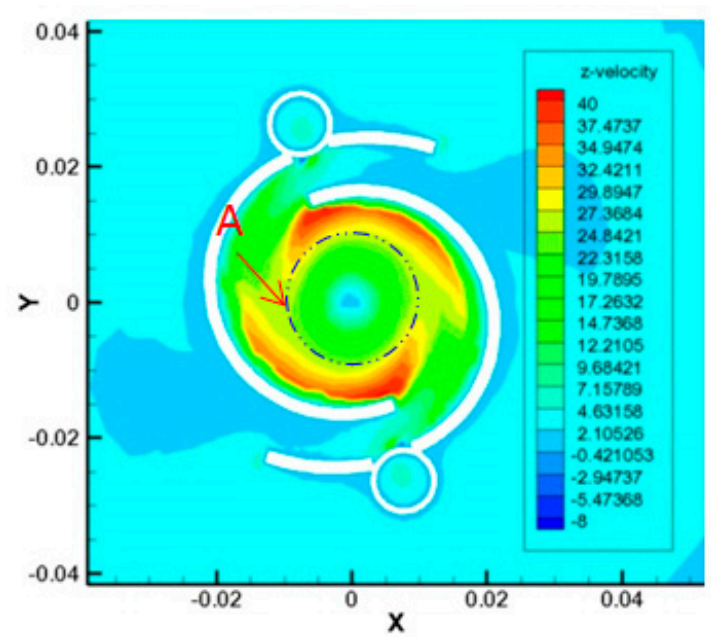

case 2

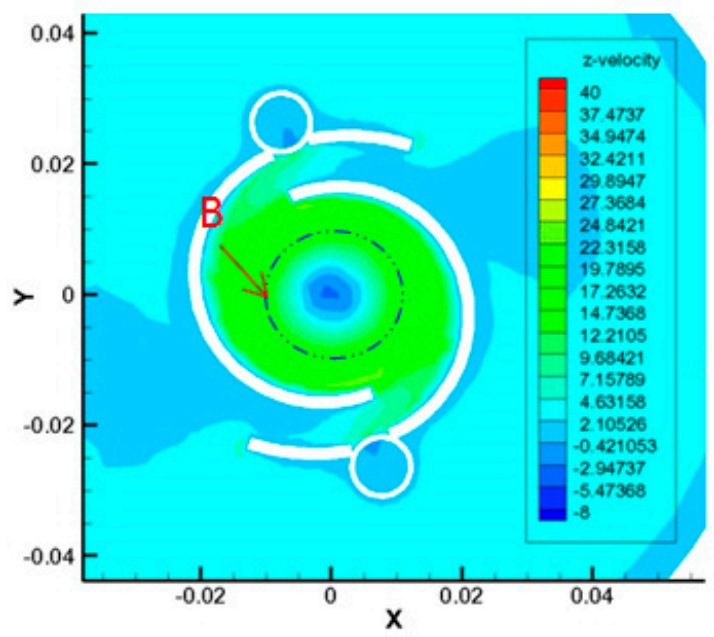

case 6

Figure 8. Sectional distribution map of axial velocity at $Z=-50 \mathrm{~mm}$. 


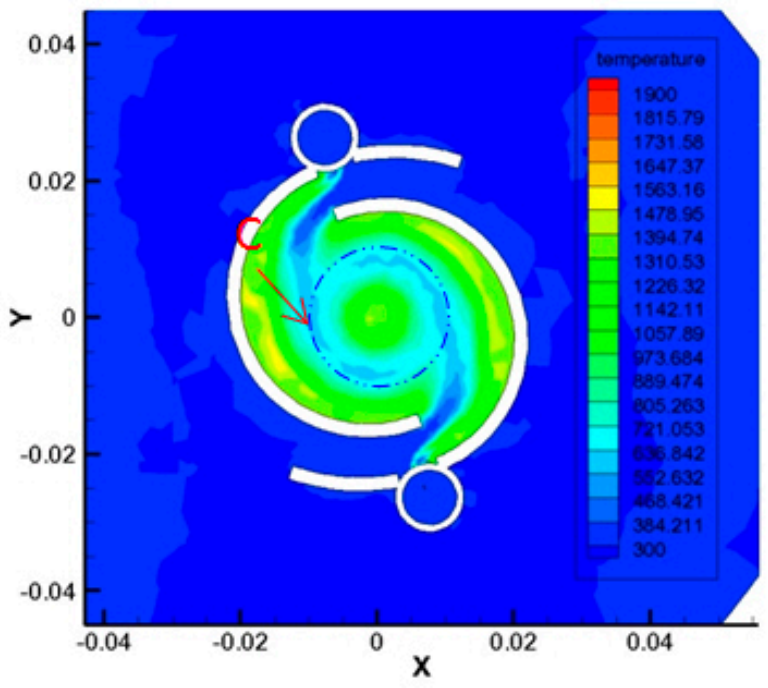

case 2

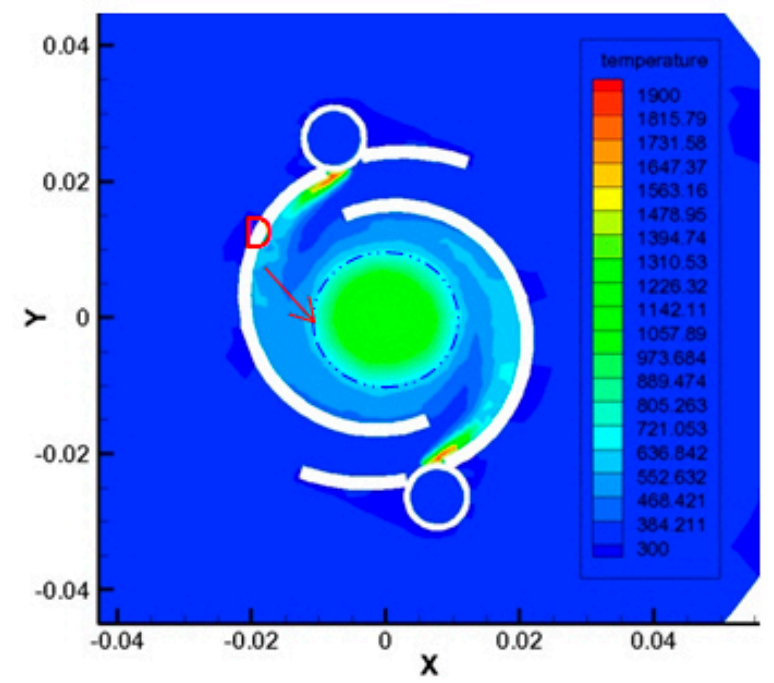

case 6

Figure 9. Sectional distribution map of temperature distribution at $Z=-50 \mathrm{~mm}$.

For case 2, the inconsistence of low reference velocity region and high temperature region in the sectional area can affect combustion stability. A small high-temperature area achieved in case 6 at lower total fuel flow rate may improve the flame stability. These phenomena can be explained by the Damkohler number analysis.

The Damkohler number [31] is usually used to judge or predict the trend of the combustion stability. To some extent, the Damkohler number is also useful to evaluate the completeness of combustion. The Damkohler number is defined as the ratio of the average local residence time $\tau_{\text {resi }}$ to the chemical kinetic time $\tau_{\text {chem }}$.

$$
D_{\text {low }}=\tau_{\text {resi }} / \tau_{\text {chem }}
$$

A larger Damkohler number is more appropriate for the combustion process because the combusting reaction become more complete with increased residence time. The longer residence time also can contribute to a sustainable flame and the stable combustion. The local residence times $\tau_{\text {resi }}$ and the chemical kinetic time $\tau_{\text {chem }}$ can be calculated by [32]:

$$
\tau_{\text {resi }}=l_{0} / v_{r m s}^{\prime}, \tau_{\text {chem }}=\delta_{L} / S_{L}
$$

then the Damkohler number is given by:

$$
D_{\text {low }}=l_{0} \cdot S_{L} /\left(v^{\prime}{ }_{r m s} \cdot \delta_{L}\right)
$$

where $l_{0}$ is the characteristic geometry length scale, $v_{r m s}^{\prime}$ is the turbulent velocity, $\delta_{L}$ is the laminar flame thickness, and $S_{L}$ is the laminar flame velocity. $v_{r m s}^{\prime}, \delta_{L}$ and $S_{L}$ are the parameters related to the thermal physical property, local velocity and temperature which can be obtained from the numerical results.

The equal-sized area marked by circle A, B, C and D are key regions affecting the development of combustion stability and are selected for Damkohler number analysis. The effect of pressure on $v^{\prime}{ }_{r m s}, \delta_{L}$ and $S_{L}$ can be neglected because the identical pressure conditions were used for both cases of 2 and 6 simulations. The equal-sized area A, B, C and $D$ results in identical values of $l_{0}$ for each case. By comparison of area $C$ and area $D$ in Figure 8, the temperature in the core region of case 6 is higher than that of case 2, leading to a larger value for $S_{L}$. The simulated results Comparison of velocity in area $\mathrm{A}$ and area $\mathrm{B}$ in Figure 7 gives an obvious lower level of the turbulence velocity in case 6 and suggests a smaller value of $v^{\prime}{ }_{r m s}$ for case 6 . For methane combustion under atmospheric pressure, the 
laminar flame thickness will decrease with the increase of temperature or equivalence ratio of the values of less than 1 [33], so $\delta_{L}$ of case 6 is smaller than that of case 2 .

Based on above analysis and the calculation of Equation (4), case 6 has a larger $D_{\text {low }}$ than that of case 2, and this suggests that the operating conditions of case 6 is more conducive to sustain a stable combustion. Consequently, the blowout performance of case 6 is better than that of case 2 under low operating conditions. The above analyses are also applicable to cases 3, 4 and 5. The coincidence of low local speed region and high temperature region in the core region with a larger Damkohler number can greatly enhance the combustion stability and improve the blowout performance of the combustor under low operating conditions.

\title{
6. Conclusions
}

To improve the combustion stability a conical swirler based on the distribution of two parts of fuel at low operating condition is proposed in this paper. The blowout performance of the conical swirler combustor is studied by a combination of experimental testing and numerical simulations. The conclusions are as follows:

1. The technique employing two parts of fuel working together at low operating condition is an effective way to enhance combustion stability and to widen the boundary of the blowout.

2. Increasing the fuel distribution ratio can enhance the combustion stability of the combustor, but also cause the NOx emission to increase.

3. The increase of the fuel distribution ratio contributes to the contact ratio among the zones with lower local velocity, higher temperature rise and larger Damkohler number, and that is an important reason for the improvement of blowout performance.

The first-hand experimental data and the conclusion drawn in this paper may form a suitable basis for future research in the stability of the low NOx emission combustor or burner, especially under low operating conditions.

Author Contributions: Investigation and writing, Y.Y. and Q.Z.; review and editing, M.Z. and J.Y.; data curation and validation, Y.Z. and L.Z. All authors have read and agreed to the published version of the manuscript.

Funding: This work was supported by National Natural Science Foundation of China, No. 50876104 and No. 51406196.

Institutional Review Board Statement: Not applicable.

Informed Consent Statement: Not applicable.

Data Availability Statement: Not applicable.

Conflicts of Interest: The authors declare no conflict of interest.

\section{Nomenclature}

\author{
Nomenclature \\ $\dot{m} \quad$ volume flow rate, $\mathrm{L} / \mathrm{min}$ \\ $R_{a} \quad$ ratio, $\%$ \\ D Damkohler number \\ $\delta \quad$ flame thickness, $\mathrm{mm}$ \\ Subscripts \\ low low operating condition \\ L laminar \\ Part, A stream from the top of cone \\ Part, B stream from the side of cone
}




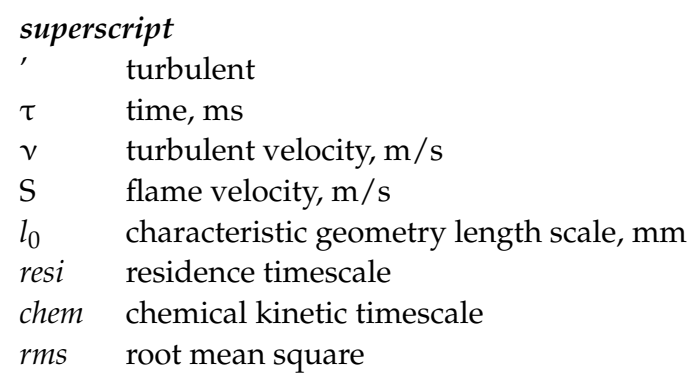

\section{References}

1. Glassman, R.A.; Yetter, N.G.; Glumac, N.G. Combustion, 5th ed.; Academic Press: Cambridge, MA, USA, 2014.

2. Lackner, M.; Palotás, A.B.; Franz, W. Combustion: From Basics to Applications; Wiley-VCH: Weinheim, Germany, 2013.

3. Huang, Y.; Yang, V. Dynamics and Stability of Lean- premixed Swirl-stabilized Combustion. Prog. Energy Combust. Sci. 2009, 35, 293-364. [CrossRef]

4. Lefebvre, A.H.; Ballal, R.D. Gas Turbine Combustion, 3rd ed.; Taylor \& Francis: Abingdon, UK, 2010.

5. Zajadatz, M.; Lachner, R.; Bernero, S.; Motz, C.; Flohr, P. Development and Design of Alstom's Staged Fuel Gas Injection EV Burner for NOx Reduction. In Proceedings of the ASME Turbo Expo 2007: Power for Land, Sea, and Air, Montreal, QC, Canada, 14-17 May 2007.

6. Domen, S.; Gotoda, H.; Kuriyama, T.; Okuno, Y.; Tachibana, S. Detection and prevention of blowout in a lean premixed gas-turbine model combustor using the concept of dynamical system theory. Proc. Combust. Inst. 2015, 35, 3245-3253. [CrossRef]

7. Taamallah, S.; Labry, Z.A.; Shanbhogue, S.J.; Ghoniem, A.F. Thermo-acoustic instabilities in lean premixed swirl stabilized combustion and their link to acoustically coupled and decoupled flame macrostructures. Proc. Combust. Inst. 2015, 35, 3273-3282. [CrossRef]

8. Zeng, Q.H.; Zheng, D.; Yuan, Y.X. Counter-rotating dual-stage swirling combustion characteristics of hydrogen and carbon monoxide at constant fuel flow rate. Int. J. Hydrogen Energy 2020, 45, 4979-4990. [CrossRef]

9. Lee, B.J.; Im, H.G. Dynamics of bluff-body-stabilized lean premixed syngas flames in a meso-scale channel. Proc. Combust. Inst. 2017, 36, 1569-1576. [CrossRef]

10. Mongia, H.; Gore, J.P.; Grinstein, F.; Gutmark, E.; Jeng, S.-M.; McDonell, V.; Menon, S.; Samuelsen, G.; Santavicca, D.; Santoro, R. Combustion Research Needs for Helping Development of Next-Generation Advanced Combustors. In Proceedings of the AIAA Joint Propulsion Conference \& Exibit, Salt Lake City, UT, USA, 8-11 July 2001.

11. Yuan, Y.; Lin, Y.; Liu, G. The Research of Combustor Dome Design with Three Swirlers on Widening the Operation Stability Range. Chin. J. Aerosp. Power 2004, 19, 142-147.

12. Sugiyama, Y.; Takamura, R.; Koide, Y.; Watanabe, T.; Hosoi, J.; Kuyama, T.; Kawano, M.; Nakahata, T. Research and development of a $1600 \mathrm{C}$-level combustor with high heat release rate. In Proceedings of the ISABE-International Symposium on Air Breathing Engines, Melbourne, Australia; 1995; pp. 1077-1087.

13. Cong, C.; Yixiang, Y.; Pengfu, X.; Dejun, Z.; Chao, Y.; Chunqing, T. A Study on Lean Blowout of Multi-vortexes-dome Model Combustor. J. Therm. Sci. 2013, 22, 366-371.

14. Zeng, Q.H.; Kong, W.J.; Sui, C.J. Effect of Confinement on Combustion Characteristics in Lean Direct Injection Combustion System. In Proceedings of the ASME Turbo Expo 2013, San Antonio, TX, USA, 3-7 June 2013. GT2013-95413.

15. Zeng, Q.; Yuan, Y. Flow dynamics of dual-stage counter-swirl combustor in different confinement spaces. Int. Commun. Heat Mass Transf. 2020, 116, 104633. [CrossRef]

16. Biagioli, F.; Guthe, F.; Schuermans, B. Combustion Dynamics Linked to Flame Behaviour in a Partially Premixed Swirled Industrial Burner. Exp. Therm. Fluid Sci. 2008, 32, 1344-1353. [CrossRef]

17. Sohn, C.H.; Cho, H.C. Numerical Analysis of Combustion Instability and Its Suppression in Gas Turbine Combustor with Swirlers Modeled on EV Premix Burners. In Proceedings of the ASME Turbo Expo 2005: Power for Land, Sea, and Air, Reno, NV, USA, 6-9 June 2005.

18. Xiaoming, S.; Yixiang, Y.; Detang, Z.; Pengfu, X.; Chunqing, T. Study on the Effects of the Dome Fuel Distribution Ratio on Lean Blowout of a Model Combustor. J. Therm. Sci. 2020, 29, 52-57.

19. Guyot, D.; Meeuwissen, T.; Rebhan, D. Staged Premix EV Combustion in Alstom's GT24 Gas Turbine Engine. In Proceedings of the ASME Turbo Expo 2012: Turbine Technical Conference and Exposition, Copenhagen, Denmark, 11-15 June 2012.

20. Döbbeling, K.; Hellat, J.; Koch, H. 25 Years of BBC/ABB/Alstom Lean Premix Combustion Technologies. J. Eng. Gas Turbines Power 2005, 129, 2-12. [CrossRef]

21. Sattelmayer, T.; Felchlin, M.P.; Haumann, J.; Hellat, J.; Styner, D. Second-Generation Low-Emission Combustors for ABB Gas Turbines: Burner Development and Tests at Atmospheric Pressure, Transactions of the ASME. J. Eng. Gas Turbines Power 1992, 114, 118-125. [CrossRef]

22. Goh, E.; Sirignano, M.; James, L.; Nair, V.; Emerson, B.; Lieuwen, T.; Seitzman, J. Prediction of minimum achievable NOx levels for fuel-staged combustors. Combust. Flame 2019, 200, 276-285. [CrossRef] 
23. Kang, M.S.; Jeong, H.J.; Farid, M.M.; Hwang, J. Effect of staged combustion on low NOx emission from an industrial-scale fuel oil combustor in South Korea. Fuel 2017, 210, 282-289. [CrossRef]

24. Paschereit, C.O.; Flohr, P.; Knopfel, H.; Geng, W.; Steinbach, C.; Stuber, P.; Bengtsson, K.; Ephraim, J.G. Combustion Control by Extended EV Burner Fuel Lance, 2002-GT-30462. In Proceedings of the ASME Turbo Expo 2002: Land, Sea and Air, Amsterdam, The Netherlands, 3-6 June 2002.

25. Houshfar, E.; Skreiberg, Ø.; Todorović, D.; Skreiberg, A.; Løvas, T.; Jovović, A.; Sørum, L. NOx emission reduction by staged combustion in grate combustion of biomass fuels and fuel mixtures. Fuel 2012, 98, 29-40. [CrossRef]

26. Adouane, B.; De Jong, W.; Van Buijtenen, J.; Witteveen, G. Fuel-NOx emissions reduction during the combustion of LCV gas in an air staged Winnox-TUD combustor. Appl. Therm. Eng. 2010, 30, 1034-1038. [CrossRef]

27. Chen, L.; Zhang, R.; Pan, J.; Wei, H. Effects of partitioned fuel distribution on auto-ignition and knocking under spark assisted compression ignition conditions. Appl. Energy 2020, 260, 114269. [CrossRef]

28. Qinghua, Z.; Wenjun, K.; Baorui, W. Effects of fuel configuration on NOx formation characteristics within a gas turbine combustor. Chin. J. Eng. Thermophys. 2011, 32, 232-235.

29. Iqbal, S.; Benim, A.C.; Fischer, S.; Joos, F.; Klu $\beta$, D.; Wiedermann, A. Experimental and numerical analysis of natural bio and syngas swirl flames in a model gas turbine combustor. J. Therm. Sci. 2016, 25, 460-469. [CrossRef]

30. Xiaoming, S.; Yixiang, Y.; Chunqing, T.; Chao, Y.; Pengfu, X. Effects of Fuel Distribution of Conical Swirler Dome on Lean Blowout of Model Combustor. Chin. J. Propuls. Technol. 2019, 40, 2262-2269.

31. Guan, Y.; Novosselov, I. Damkohler Number Analysis in Lean Blow-Out of Toroidal Jet Stirred Reactor. J. Eng. Gas Turbines Power 2018, 140, 104501. [CrossRef]

32. Turns, S.R. An Introduction to Combustion: Concepts and Applications, 3rd ed.; McGraw-Hill Education: New Delhi, India, 2012.

33. Andrews, G.E.; Bradley, D. The Burning Velocity of Methane-Air Mixtures. Combust. Flame 1972, 19, 275-288. [CrossRef] 